\title{
Nitride-based laser diodes and superluminescent diodes
}

\author{
P. Perlin, ${ }^{* 1,2}$ S. Stańczyk, ${ }^{1}$ A. Kafar, ${ }^{1}$ A. Bojarska, ${ }^{1}$ Ł. Marona, ${ }^{1}$ R. Czernecki, ${ }^{2}$ G. Targowski, ${ }^{2}$ G. Muzioł, ${ }^{1}$ \\ H. Turski, ${ }^{1}$ E. Grzanka, ${ }^{1}$ S. Grzanka, ${ }^{1,2}$ P. Wiśniewski, ${ }^{1,2}$ S. Najda, ${ }^{2}$ T. Czyszanowski, ${ }^{4}$ M. Leszczyński, ${ }^{1,2}$ \\ C. Skierbiszewski, ${ }^{1}$ R. Kucharski, ${ }^{3}$ and T. Suski ${ }^{1}$ \\ ${ }^{1}$ Institute of High Pressure Physics PAS, Sokołowska 29/37, 01-142 Warsaw, Poland \\ ${ }^{2}$ TopGaN Ltd. , Warsaw, Poland \\ ${ }^{3}$ Ammono S.A., Warsaw, Poland \\ ${ }^{4}$ Institute of Physics, Lodz University of Technology, Wolczanska 219, 93-005 Lodz, Poland
}

Received August 15, 2013; accepted March 31, 2014; published March 31, 2014

\begin{abstract}
We report on the development of nitride laser diode technology leading towards higher optical power, better quality and larger versatility of these devices. In particular we discuss new concepts introduced in the Institute of High Pressure Physics "Unipress" such as: a new design of the laser diode waveguide by making use of plasmonic substrate properties of the material, design and fabrication of high optical power laser diode arrays, construction of high power nitride based superluminescent diodes and high-indium content devices grown by molecular beam epitaxy.
\end{abstract}

Nitride laser diodes, based on InGaN/GaN/AlGaN heterostructures, were demonstrated almost 20 years ago and introduced to the mass market in the middle of first decade of this century [1]. These devices are today indispensable for optical data storage (BluRay standard), new generation of multicolor displays, fast printing, chemical and biological detection and analysis. From the point of view of optical engineering and material science these devices still pose a number of fundamental challenges and although this technology has clearly reached a certain level of maturity, yet it is still not comparable with the sophistication of GaAs optoelectronics. However, steady progress in $\mathrm{GaN}$ substrate growth and the development of nitride epitaxial technologies makes it possible nowadays to think about new potentialities and new applications of $\mathrm{GaN} / \mathrm{InGaN}$ based laser diodes. In this paper we discuss few paths of the device development carried on in the Institute of High Pressure Physics "Unipress" including:

- new plasmonic design of a laser diode waveguide,

- high optical power arrays of nitride laser diodes,

- nitride based superluminescent diodes,

- novel design of a blue laser diode grown by molecular beam epitaxy.

\footnotetext{
* E-mail: piotr@unipress.waw.pl
}

The optimum design of a waveguide in InGaN laser diodes is always a compromise between the optical parameters and material quality of the system. The refractive index step needed to confine light inside the laser diode waveguide is commonly achieved by growing $\mathrm{AlGaN} / \mathrm{GaN} / \mathrm{AlGaN}$ layers [2]. Unfortunately, a high lattice mismatch between $\mathrm{GaN}$ and $\mathrm{AlN}$ (2.4\%) generates tensile strain. In thick $\mathrm{AlGaN}$ layers it leads to wafer bowing and layer cracking [3]. Furthermore, the GaN substrate, which is transparent for traveling light, may form a parasitic waveguide resulting in increased optical losses and a reduced optical confinement factor [4-5].

To solve the above-mentioned problem, in Unipress, we investigate the use of gallium nitride substrates with a reduced refractive index. This effect is attained by high a doping level resulting in the electron concentration (from $5 \times 10^{19} \mathrm{~cm}^{-3}$ up to $1 \times 10^{20} \mathrm{~cm}^{-3}$ ) and is known as a plasmonic effect. Thanks to the light-confining ability of these substrates we were able to reduce the AlGaN cladding thickness from the initial $800 \mathrm{~nm}$ to $200 \mathrm{~nm}$ with no visible deterioration of the laser parameters [6]. For example, in Fig. 1 we can see no difference in the nearfield pattern of laser diodes with various thickness of cladding layer. The laser diode structures obtained by this method are less bowed, and have a lower number of defects than a traditionally designed device with AlGaN claddings.

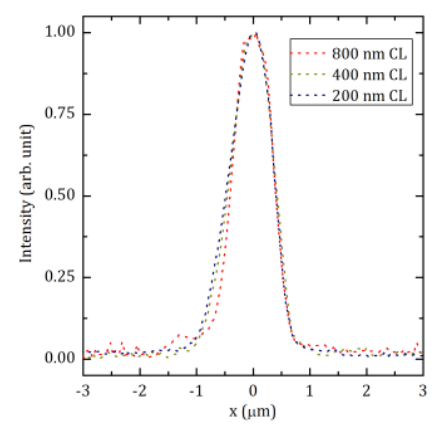

Fig. 1. Intensity profiles of the near-field pattern in the transversal direction of the laser diodes with various thickness of cladding layer. 
There is a growing interest in the realization of very high optical power DC operated InGaN laser diodes for optical displays (laser displays and movie projectors), printing, lithography and marking systems, solid state lasers pumping and others. Unfortunately, the maximum power of the laser diode is limited by Catastrophic Optical Mirror Damage (COMD) leading to the facet melting above a threshold power density of around $50 \mathrm{MW} / \mathrm{cm}^{2}$ [7]. In addition, the very high current required for high optical power operation is known as a major factor contributing to the life-time reduction of the device [8]. The proposed solution to overcome the above mentioned problems is to consider using laser diode arrays. The advantage of a laser array is achieving a robust, high power device that is relatively easy to manufacture [9]. However, fabricating nitride laser arrays has been limited by insufficiently low and non-uniform defect density GaN substrates. By using a low defect dislocation Ammono-GaN substrate combined with the state of the art MOVPE growth we realized a 16-emitters laser diode array, which reached an optical power of $4 \mathrm{~W}$, at room temperature and continuous wave operation. The diode was mounted into a CS-like package with two-side copper radiators. The optical parameters of this array are shown in Fig. 2.

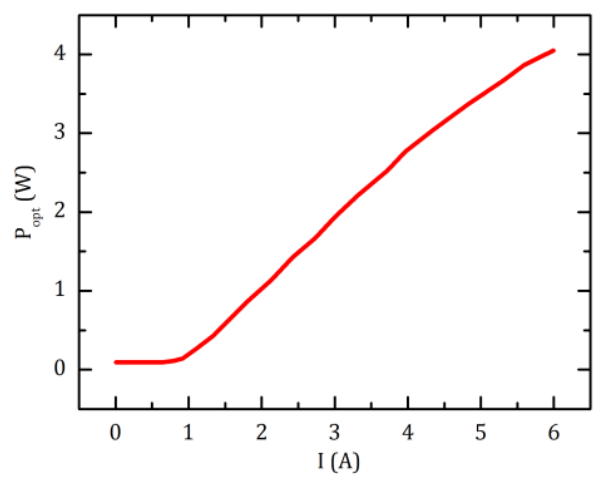

Fig. 2. Optical power as a function of a drive current for laser diode array.

An additional field of research explored by IHPP PAS is the fabrication and optimization of superluminescent diodes (SLDs) [10]. SLDs are semiconductor light sources which combine features of LED and laser diodes (LDs): high spatial coherence, but at the same time low time coherence [11]. These features are demanded in applications such as fibre-optic gyroscopes (FOG) [12], optical coherence tomography (OCT) [13] and picoprojectors. This devices are fabricated using the technology developed for LDs (separate confinement heterostructure with a ridge waveguide). The only difference is that the waveguide is defined in a way that prevents light oscillation in the device [14].

SLDs fabricated in IHPP PAS are based on $\mathrm{j}$-shape waveguide geometry, which is shown in Fig. 3. One half of the waveguide, from the rear-facet-side, is straight as in standard LDs. The other part is bent towards the front facet, reaching angles $\alpha$ from $5^{\circ}$ to $8^{\circ}$. Such geometry works as a double-pass amplifier. This means that light can be amplified on a longer path than $\mathrm{L}$ and more output power can be achieved.

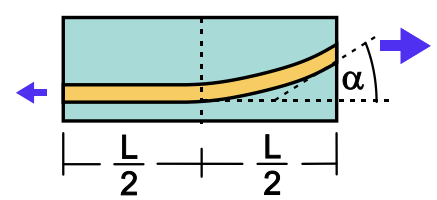

Fig. 3. Scheme of 'j-shaped' waveguide geometry.

In Fig. 4 we show the basic parameters of a selected device, which was $1 \mathrm{~mm}$ long with a bent angle of $7.5^{\circ}$. The device was mounted in a two-side copper heat-sink and DC operated. One can see that even at a current of $450 \mathrm{~mA}$ the device is not lasing and the spectra do not show any dominant cavity mode. This device allowed reaching optical powers higher than $200 \mathrm{~mW}$, which is a world-class result [15].
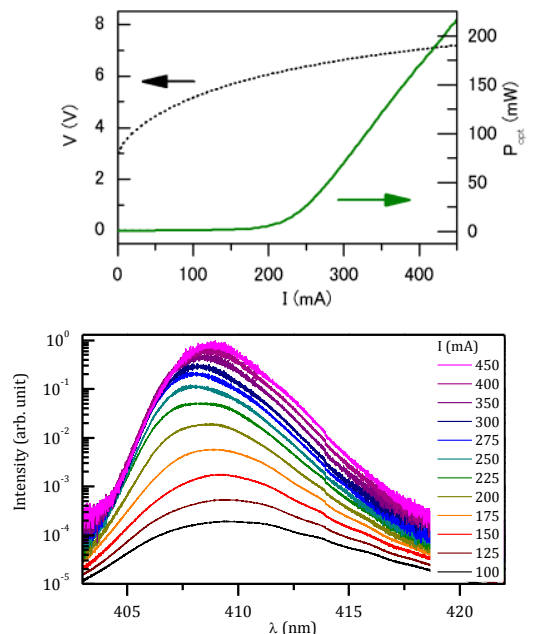

Fig. 4 a) Current - voltage and optical power - current dependence of superluminescent diode and b) emission spectra measured for different applied currents.

Molecular beam epitaxy is known to provide an ultimate quality in growing heteroepitaxial structures thanks to the unique sharpness of interfaces and outstanding control of growth parameters. However, in the case of nitride semiconductors, this method for long time has not been successfully implemented for a fabricating optoelectronic devices.

First world nitride based laser diodes (LDs) operated at 408-420nm grown by Plasma Assisted Molecular Beam Epitaxy (PAMBE) were demonstrated at IHPP PAS in 2004 [16]. The advantages of PAMBE are (i) low growth temperature, and (ii) absence of hydrogen during growth the activation of p-type conductivity is not necessary. 
Recent progress in the growth of nitride based LDs made by PAMBE operating in the range $430 \mathrm{~nm}-460 \mathrm{~nm}$ is related with an understanding growth mechanism of InGaN. The key element to achieve lasing for wavelengths above $430 \mathrm{~nm}$ was a substantial increase in the nitrogen flux available for growth in PAMBE maintaining a relatively high growth temperature [17][19]. The increase of $\mathrm{N}$ flux is beneficial for efficient InGaN quantum wells and thick, high In content InGaN layers. High $\mathrm{N}$ flux during growth is also important to improve the InGaN/GaN interface roughness between the quantum wells and barriers. Making use of high quality growth of InGaN layers by PAMBE, we proposed a new design of LDs with InGaN waveguides and $\mathrm{GaN}$ claddings [20]. The elimination of Al from LDs claddings decreased the voltage across the LDs.

In Figure 5 we present L-I-V (light-current-voltage) characteristics and spectra below and above lasing in DC mode of $\mathrm{AlGaN}$ cladding free LDs. The lasing wavelength for these LDs was 460nm and a maximum output power of $80 \mathrm{~mW}$ was measured. The elimination of $\mathrm{Al}$ from claddings also increased the lifetime of PAMBE laser diodes above $2000 \mathrm{~h}$.

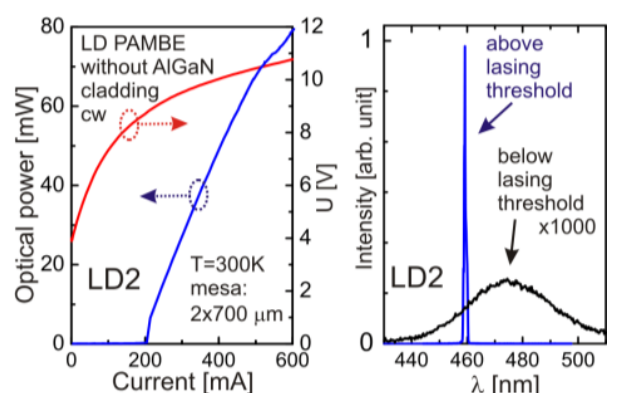

Fig. 5. a) The L-I-V characteristics and b) emission spectra below and above lasing threshold of AlGaN-cladding free PAMBE LDs operating at $460 \mathrm{~nm}$.

The information provided in this paper shows the intense and multidirectional work done in Institute of High Pressure Physics on the subject of nitride light emitters. We proposed novel methods improving the operation parameters of nitride laser diodes: plasmonic substrates and AlGaN-free claddings. We were also able to present the record-breaking high-power superluminescent diodes.

The work was supported by:

- The National Science Center of Poland within the project NN515 506540 and by the National Centre for Research and Development within the project E!6368/12/NCBiR/11.

- Wroclaw Research Centre EIT+ within the project "The Application of Nanotechnology in Advanced Materials" - NanoMat (POIG.01.01.02-02-002/08) cofinanced by the European Regional Development
Fund (operational Programme Innovative Economy, 1.1.2).

- The National Center for Research and Development within the project: POLARPOL, PBS1/B5/8/2012.

\section{References:}

[1] H. Morkoc, Handbook of Nitride Semiconductors and Devices, vol. 3, chapter 2 (Wiley-VCH 2009).

[2] S. Nagahama, M. Sano, T. Yanamoto, D. Morita, O. Miki, K. Sakamoto, M. Yamamoto, Y. Matsuyama, Y. Kawata, T. Murayama, T. Mukai, Proc. SPIE 4995, 108 (2003).

[3] M. Sarzyński, M. Kryśko, G. Targowski, R. Czernecki, A. Sarzyńska, A. Libura, W. Krupczyński, P. Perlin, M. Leszczyński, Appl. Phys. Lett. 88, 121124 (2006).

[4] G.A. Smolyakov, P.G. Eliseev, M. Osinski, IEEE J. Quantum Electron. 41(4), 517 (2005).

[5] P. Perlin, K. Holc, M. Sarzynski, W. Scheibenzuber, L. Marona, R. Czernecki, M. Leszczynski, M. Bockowski, I. Grzegory, S. Porowski, G. Cywinski, P. Firek, J. Szmidt, U. Schwarz, T. Suski, Appl. Phys. Lett. 95, 261108 (2009).

[6] S. Stańczyk, T. Czyszanowski, A. Kafar, R. Czernecki, G. Targowski, M. Leszczyński, T. Suski, R. Kucharski, P. Perlin, Appl. Phys. Lett. 102, 151102 (2013).

[7] N. Ikeda, T. Mizuno, N. Takeya, S. Goto, S. Ikeda, T. Fujimoto, Y. Ohfuji, T. Hashizu, Phys. Status Solidi C 1, 1461 (2004).

[8] M. Meneghini, N. Trivellin, K. Orita, S. Takigawa, T. Tanaka, D. Ueda, G. Meneghesso, E. Zanoni: Appl. Phys. Lett. 97, 263501 (2010).

[9] P. Perlin, L. Marona, K. Holc, P. Wisniewski, T. Suski, M. Leszczynski, R. Czernecki, S. Najda, M. Zajac, R. Kucharski, Appl. Phys. Expr. 4, 062103 (2011).

[10] K. Holc, Ł. Marona, R. Czernecki, M. Boćkowski, T. Suski, S. Najda, P. Perlin, J. Appl. Phys. 108, 013110 (2010).

[11] G.A. Alphonse: Proc. SPIE 4648, 125 (2002).

[12] P.R. Ashley, M.G. Temmen, M. Sanghadasa: Proc. SPIE 4648, 104 (2002).

[13] J.M. Schmitt: IEEE J. Sel. Top. Quant. Electron. 5, 1205 (1999).

[14] A. Kafar, S. Stańczyk, S. Grzanka, R. Czernecki, M. Leszczyński, T. Suski, P. Perlin, J. Appl. Phys. 111, 083106 (2012).

[15] A. Kafar, S. Stańczyk, G. Targowski, T. Oto, I. Makarowa, P. Wisniewski, T. Suski, P. Perlin, Appl. Phys. Expr. 6, 092102 (2013).

[16] C. Skierbiszewski, Z.R. Wasilewski, M. Siekacz, A. Feduniewicz, P. Perlin, P. Wisniewski, J. Borysiuk, I. Grzegory, M. Leszczynski, T. Suski, S. Porowski, Appl. Phys. Lett. 86, 11114 (2005).

[17] H. Turski, M. Siekacz, M. Sawicka, G. Cywinski, M. Krysko, S. Grzanka, J. Smalc-Koziorowska, I. Grzegory, S. Porowski, Z.R. Wasilewski, C. Skierbiszewski, J. Vac. Sci. Technol. B 29, 03C136 (2011).

[18] H. Turski, M. Siekacz, M. Sawicka, Z. R. Wasilewski, S. Porowski, C. Skierbiszewski, Jap. J. Appl. Phys. 52, 08 JE02 (2013).

[19] H. Turski, M. Siekacz, Z.R. Wasilewski, M. Sawicka, S. Porowski, C. Skierbiszewski, J. Cryst. Growth 367, 115 (2013).

[20] C. Skierbiszewski, M. Siekacz, H. Turski, G. Muziol, M. Sawicka, P. Wolny, G. Cywiński, L. Marona, P. Perlin, P. Wiśniewski, M. Albrecht, Z.R. Wasilewski, S. Porowski, Appl. Phys. Expr. 5, 112103 (2012). 